\title{
Digestion, defecation and food passage rate in the insectivorous bat Myotis myotis
}

\author{
Jerzy STALIŃSKI*
}

\begin{abstract}
Staliński J. 1994. Digestion, defecation and food passage rate in the insectivorous bat Myotis myotis. Acta theriol. 39: 1-11.

The coefficient of dry mass digestibility (DMD) in the insectivorous bat Myotis myotis (Borkhausen, 1797), fed American cockroaches, is 69.3\%. This is comparable with the average digestibility and assimilation coefficients in insectivorous mammals and birds, but it is much lower than estimated in previous studies on insectivorous bats. The rate of passage of food marked with basic fuchsin $\left(t_{5}=25, t_{50}=44, t_{90}=\right.$ 77 minutes) and the defecation rate indicate extremely rapid digestion of food, which is connected with the feeding and foraging strategies of insectivorous bats. It is concluded, that previous estimations of bats' food consumption under natural conditions were lowered by the assumption of high digestibility of food or insignificant amount of feces defecated outside the rest place.
\end{abstract}

Department of Ecosystem Studies, Jagiellonian University, Ingardena 6, PL 30-060 Kraków, Poland

Key words: Myotis myotis, assimilation efficiency, feeding strategy

\section{Introduction}

Insectivorous bats have diverse trophic specializations involving composition of diet, foraging strategies and use of the habitat's food resources. Many behavioral and ecological studies provide evidence for bats' specialization in "rapid feeding", i.e. adaptation to quick catching and digestion of food (Fenton 1982). Use of flight as a means of locomotion is tied to a reduction in the size and volume of the intestines and of the mass of food remaining in the gut (Barry 1976, Sibly 1981). These adaptations increase the digestion rate but it may lower the digestibility coefficient.

The high variability of digestibility parameters and their great dependence on measurement methods (see Warner 1981 for review) make it difficult to compare digestive strategies. Moreover, the use in feeding experiments of unnatural diets affect the acceptability of the high digestibility of food in insectivorous mammals (Grodziński and Wunder 1975, Anthony and Kunz 1977, Kunz 1980, Kunz and

\footnotetext{
*Present address: Department of Zoology and Ecology, Agricultural University, Mickiewicza 24/28, PL 30-059 Kraków, Poland; E-mail: rzstalin@cys-kr.edu.pl
} 
Nagy 1988, and others). This assumption may lead to miscalculations of bats consumption, energy budget, optimal foraging strategy, etc.

The aim of this study was to determine the digestibility coefficient, food passage time through the gut, and defecation rate in the mouse-eared bat Myotis myotis (Borkhausen, 1797) using food similar to the natural diet and to compare these parameters with those in other insectivorous mammals. Secondly, this study makes possibility for testing ash-tracer technique, which can be useful in estimation of assimilation efficiency in free-living bats.

\section{Material and methods}

\section{Experimental animals}

Nine Myotis myotis were captured at the Krakowsko-Wieluńska Upland in central Poland in September 1988 . The animals were housed in cages singly, at room temperature $\left(22^{\circ} \mathrm{C}\right)$ and natural photoperiod. They were fed American cockroaches Periplaneta americana at their normal time of foraging (between 19.30 and 20.30) in an amount enabling them to maintain constant body weight (15-20\% of prefeeding body weight, Staliński, unpubl.). Water was given ad libitum. The acclimation period was 10 days. Average body weight during the experiments was $21.0 \mathrm{~g}(\mathrm{SD}=1.5)$. After the completion of experiments the bats were freed at the place of capture.

\section{Digestibility of food}

Balance method. Seven series of 24-hours measurements of dry mass digestibility were done. Samples of food, collected feces and uneaten food were dried to constant mass at $60^{\circ} \mathrm{C}$ and then weighed. The digestibility coefficient was calculated according to the formula:

$$
\mathrm{DMD}=(1-\mathrm{F} / \mathrm{C}) \times 100
$$

where: DMD - coefficient of dry mass digestibility (\%), F - dry mass of feces, C - dry mass of food eaten

The coefficient of assimilation was estimated by assuming its value at $97 \%$ of DMD (Grodziński and Wunder 1975).

Indicator method. There were two series of five-day measurements using ash as a natural indicator. Samples of food (10), feces (36; 2 for each measurement) and uneaten food (10) were burnt in a muffle furnace at $500^{\circ} \mathrm{C}$ for 10 hours. The digestibility coefficient was calculated according to the formula (Johnson and Maxell 1966, Soholt 1973):

$$
\operatorname{DMD}_{\mathrm{A}}=\left(1-y_{\mathrm{o}} \times y_{\mathrm{n}} / y\right) \times 100
$$

where: $\mathrm{DMD}_{\mathrm{A}}$ - coefficient of dry mass digestibility (\%), $y_{0}$ - ash fraction in food, $y$ - ash fraction in feces, $y_{\mathrm{n}}$ - coefficient reflecting the fraction of ash undigested calculated as the ratio of ash defecated to ash consumed.

\section{Rate of defecation}

The defecation rate was determined by collecting feces every 30 minutes for 11 hours after feeding and after 24 hours from the beginning of the experiment. The collected feces were dried to constant mass at $60^{\circ} \mathrm{C}$ and weighed.

\section{Food passage time through the gastrointestinal tract}

Basic fuchsin solution injected into the first portion of food given (about $4 \%$ of the total food consumed) was used as an indicator (Castle 1956, Kostelecka-Myrcha and Myrcha 1964, modified). Feces were collected as described above. The feces were mixed with $0.15 \mathrm{cc}$ water per $0.01 \mathrm{~g}$ dry faecal mass and centrifuged to separate unabsorbed marker from initially stained parts of food. Undigested 
parts were next examined under a dissecting microscope at 4-25 magnitude. The amount of indicator absorbed by undigested food was determined according to a ten-grade optical scale (estimated as fraction of stained parts). The results were converted into per cents taking into account the mass of the feces samples. The total amount of the indicator defecated by an animal during a 24-hour period was assumed to be $100 \%$. Food passage rate was calculated only in bats active for the first few hours after feeding. The results from bats which returned after feeding to sleep or lethargy were excluded from calculations.

\section{Statistical calculations}

Two-way ANOVA without replications was used to test for differences in DMD between animals and experimental series. The significance of differences between the digestibility coefficients calculated by the balance and indicator methods was determined by one-way ANOVA (Sokal and Rohlf 1981). Data are presented as mean $\pm \mathrm{SD}$.

\section{Results}

\section{Digestibility of food}

Average daily food consumption was $3.80 \pm 0.21 \mathrm{~g}$ which was equal to $1.17 \pm 0.15 \mathrm{~g}$ dry mass of food. This corresponded to $0.18 \mathrm{~g}$ and $0.06 \mathrm{~g}$ per gram of bats' body weight, respectively. Bats defecated $0.36 \pm 0.08 \mathrm{~g}$ dry mass per day. The coefficients of food digestibility amounted to $69.3 \pm 6.6 \%$ (DMD) and $68.6 \pm 4.9 \%\left(\mathrm{DMD}_{\mathrm{A}}\right)$ and did not differs significantly $\left(p=0.613\right.$ ). The correction for digestibility of ash $\left(y_{n}\right)$ was 0.78 . The coefficient of assimilation estimated from DMD was $67.2 \%$.

There were no statistically significant differences of DMD between animals ( $p=0.346$ ), however, significant differences were found between experimental series - successive measurements done every 24 hours $(p=0.0002)$.

\section{Defecation rate}

Five series of measurements were taken, altogether 43 measurements of the defecation rate. The average amount of food eaten was $4.31 \pm 0.14 \mathrm{~g}$. The bats defecated mainly during the first 5 hours after feeding ( $71 \%$ of total mass of feces; Table 1). The beginning of nocturnal activity was connected with defecation of the food remaining in the gut: about $10 \%$ of the dry mass of feces was defecated during the last two hours of the experiment.

\section{Rate of food passage through the gastrointestinal tract}

Four series of measurements were taken, altogether 30 measurements in the active bats. The first portion of defecated feces did not contain indicator and consisted of the remaining food eaten during the previous day. The first fraction of feces with indicator was defecated during first 30 minutes after the beginning of feeding. The average period for passing $5 \%$ indicator $\left(\mathrm{t}_{5}\right)$ was 25 minutes. The distribution of food passage rates (Fig. 1) showed extremely quick passage of a considerable fraction of marked food ( $\mathrm{t}_{50}=44$ minutes, $\mathrm{t}_{90}=77$ minutes), and the retention of a small amount of marked food in the gut. 


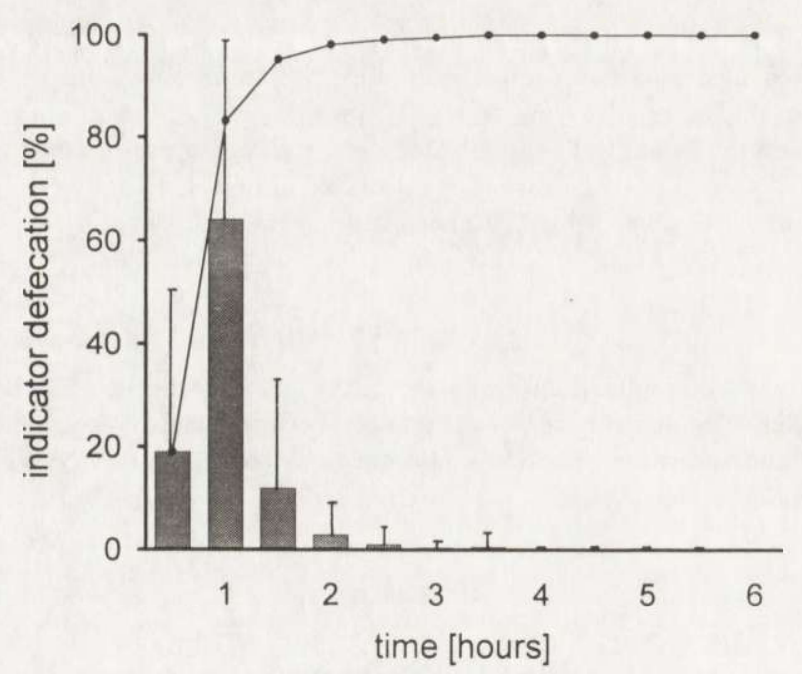

Fig. 1. Rate of food passage through the gastrointestinal tract in Myotis myotis. B - defecation of indicator $(+\mathrm{SD})$ per 30 -minutes periods as a percentage of total defecation of indicator, line cumulative percent of defecation of indicator.

Table 1. Mean $(n=43)$ and cumulative defecation rate in nine Myotis myotis as percentage of 24-hr faecal production.

\begin{tabular}{lrcc}
\hline \multirow{2}{*}{$\begin{array}{l}\text { Hours after } \\
\text { initial feeding }\end{array}$} & \multicolumn{3}{c}{ Faecal production (\%) } \\
\cline { 2 - 4 } & mean & SD & cumulative \\
\hline 1 & 14.7 & 7.4 & 14.7 \\
2 & 19.7 & 6.5 & 34.4 \\
3 & 16.0 & 5.7 & 50.4 \\
4 & 11.6 & 6.7 & 62.0 \\
5 & 9.5 & 7.8 & 71.5 \\
6 & 6.6 & 4.8 & 78.1 \\
7 & 5.9 & 5.0 & 84.0 \\
8 & 3.9 & 5.5 & 87.9 \\
9 & 0.6 & 2.0 & 88.5 \\
10 & 1.0 & 2.5 & 89.5 \\
11 & 0.2 & 1.0 & 89.7 \\
$12-24$ & 10.6 & 6.3 & 100 \\
\hline
\end{tabular}

\section{Discussion}

\section{Food digestibility}

Most of the previous studies on insectivorous bats used Tenebrio molitor larvae, a diet different from the natural one (high fat content and caloric value; see Kunz 1988 for comparison). Grodziński and Wunder (1975) and Hanski (1984) pointed 
Table 2. Digestibility of food in insectivorous bats, measured as a percentage of dry matter (DMD) or gross energy (DE) digestibility. BW - body weight (g), in the case of lack of source data, mean body mass for species are given in parentheses (Kowalski and Ruprecht 1981).

\begin{tabular}{|c|c|c|c|c|}
\hline Species and diet & BW & DMD & $\mathrm{DE}$ & Source \\
\hline \multicolumn{5}{|l|}{ Artificial food } \\
\hline Eptesicus fuscus & 15 & & $75-82$ & Pagels and Blem 1973 \\
\hline \multicolumn{5}{|l|}{ Mealworm larvae } \\
\hline Vespertilio pipistrellus & $(6.4)$ & 81.4 & & Alekseeva et al. 1980 \\
\hline Lasionycteris noctivagans & 7.7 & & 88.6 & Neuhauser and Brisbin 1969 \\
\hline \multirow[t]{2}{*}{ Myotis lucifugus } & 7.9 & 87.9 & 91.2 & O'Farell et al. 1971 \\
\hline & $7-10$ & & 88.2 & Barclay et al. 1991 \\
\hline Myotis thysanoides & 8.4 & 84.2 & 90.8 & O'Farell et al. 1971 \\
\hline Lasiurus cinereus & 23.6 & & 91.0 & Brisbin 1966 \\
\hline Myotis myotis & 28.9 & 86.1 & 89.8 & Czerwony 1976 \\
\hline Nyctalus noctula & $(30.5)$ & 79.1 & & Alekseeva et al. 1980 \\
\hline Nyctalus lasiopterus & $(58.5)$ & 76.5 & & Alekseeva et al. 1980 \\
\hline \multicolumn{5}{|l|}{ Moths } \\
\hline Myotis lucifugus & $7-10$ & & 74.9 & Barclay et al. 1991 \\
\hline Myotis evotis & $7-10$ & & 78.3 & Barclay et al. 1991 \\
\hline Myotis volans & $7-10$ & & 77.0 & Barclay et al. 1991 \\
\hline \multicolumn{5}{|l|}{ American cocroach } \\
\hline Myotis myotis & 21.1 & 69.3 & & this study \\
\hline
\end{tabular}

to the assimilation coefficient's dependence on diet, and the limited usefulness of data obtained under experimental conditions. Moderately chitinous imagos of Periplaneta americana, fed a diverse diet of plants and meat, were indicated as one of the experimental diets most similar to the natural one. In this study, balance and indicator methods were used to measure dry mass instead of energy digestibility. However, Grodziński and Wunder (1975) found that digestibility of energy and of dry mass were usually very similar, and that the difference between assimilation and digestibility coefficients was $2-3 \%$. The error for estimates of the assimilation coefficient was very low in comparison with changes caused by food quality, experimental conditions, etc.

In M. myotis, fed American cockroaches, the digestibility coefficient (DMD) was $13.2 \%$ lower than the average dry mass digestibility in 6 bat species fed mealworm larvae $(82.5 \%$; Table 2$)$ and slightly lower than coefficient of energy digestibility (DE) estimated by Barclay et al. (1991) in 3 Myotis species fed on moths (note that DMD is usually $3-5 \%$ lower than DE). The food assimilation coefficient $(67.2 \%)$ approached the average value of the energy assimilation coefficient in insectivorous birds fed insects $(73.6 \%$, from data by Castro et al. 1989) and in shrews (72.8\%, Table 3). These data show that the assimilation coefficient in small insectivorous mammals is strongly affected by the type of food (chemical composition and chitinization of insects) and that under natural conditions it is much lower 
than estimated in previous studies (85\%, Grodziński and Wunder 1975; 88\%, Anthony and Kunz 1977). This imply, that the previous estimations of the amount of food consumed by free-living bats were lowered. The indicator method has the advantage of using the tracer which can be measured in studies on digestive efficiency in the field. The lack of differences between digestibility coefficients estimated by balance and indicator methods and the low ash digestibility (high $y_{\mathrm{n}}$ correction factor) indicates, that the ash-tracer technique can give sufficient estimates and can be used in field studies.

It seems that differences between the 24-hour series in food digestibility were caused by changes in the activity of bats. If evening activity was delayed, a fraction of the feces remaining in the intestines and usually defecated during the last two hours of the experiment (about 10\%) might be defecated after the end of 24-hour measurement. That could increase the digestibility coefficient. A similar phenomenon in Myotis lucifugus was described by Brisbin (1966).

Table 3. Digestibility and assimilation efficiency in small insectivorous mammals feeding on insects. Coefficients of digestibility (D) and assimilation (A) calculated as percentage of: gross energy (E), dry matter (DM) or carbon (C). BW - body weight (g); ${ }^{1}$ experimental food: beetles Sphaeridium sp., cocroach Leucophaea maderae, sawfly cocoons Neodiprion sertifer, sawfly larvae Pristiphora erichsonii, insect larvae Calliphora erythrocephala and Tenebrio molitor, locust Locusta migratoria, termite Trinervitermes sp.; ${ }^{2}$ recalculated after Grodziński and Wunder (1975): A [\%] $=0.97 \mathrm{D}[\%]$.

\begin{tabular}{lllllll}
\hline Species & BW & Food type $^{1}$ & Method & D & A & Source \\
\hline Sorex minutissimus & 2.5 & ant pupae & C & & 73.0 & Hanski 1984 \\
Sorex minutus & 2.7 & ant pupae & C & & 83.3 & Hanski 1984 \\
& 2.7 & sawfly cocoons & C & & 85.2 & Hanski 1984 \\
Microsorex hoyi & 2.7 & beetles & C & & 61.7 & Hanski 1984 \\
Sorex cinereus & 3.5 & sawfly larvae & E & 83 & $80.5^{2}$ & Buckner 1964 \\
Sorex caecutiens & 3.6 & sawfly larvae & E & 93 & $90.2^{2}$ & Buckner 1964 \\
& 4.9 & ant pupae & C & & 83.0 & Hanski 1984 \\
Sorex arcticus & 4.9 & sawfly cocoons & C & & 85.3 & Hanski 1984 \\
Sorex araneus & 4.9 & beetles & C & & 54.2 & Hanski 1984 \\
& 5.4 & sawfly larvae & E & 88 & $85.4^{2}$ & Buckner 1964 \\
& 8.5 & insect larvae & DM & 91.2 & $88.5^{2}$ & Hawkins and Jewell 1962 \\
Sorex isodon & 8.9 & ant pupae & C & & 74.5 & Hanski 1984 \\
& 8.9 & sawfly cocoons & C & & 80.1 & Hanski 1984 \\
Neomys fodiens & 8.9 & beetles & C & & 47.0 & Hanski 1984 \\
& 11.1 & ant pupae & C & & 70.7 & Hanski 1984 \\
& 11.1 & sawfly cocoons & C & & 76.5 & Hanski 1984 \\
Blarina brevicauda & 11.1 & beetles & C & & 46.8 & Hanski 1984 \\
Elephantulus edwardii & 12.4 & insect larvae & E & 92.3 & $89.5^{2}$ & Hawkins and Jewell 1962 \\
& 12.4 & insect larvae & DM & 88.0 & $85.4^{2}$ & Hawkins and Jewell 1962 \\
& 17.8 & ant pupae & C & & 71.0 & Hanski 1984 \\
& 20.1 & sawfly cocoons & E & 78 & $75.7^{2}$ & Buckner 1964 \\
& 38 & cocroach & DM & & 71 & Woodall and Currie 1989 \\
& 38 & termite & DM & & 60 & Woodall and Currie 1989 \\
& & & & & & Woodall and Currie 1989 \\
\hline
\end{tabular}


M. myotis discarded the less digestible, chitinous parts of the insects, mainly the legs and wings. Similar selectivity has been observed in many species of insectivorous mammals (e.g. Kunz and Whitaker 1983, Rabinowitz and Tuttle 1982, Woodall and Currie 1989).

\section{Food passage time}

The food passage rate correlates negatively with body weight (Kostelecka-Myrcha and Myrcha 1964), but it is variable even under constant conditions (Warner 1981). The food passage rate in insectivorous bats is very high (Table 4) what correspond to the morphology of the alimentary tract - a very short small intestine, the absence of a caecum, a very short rectal segment and an increase in the absorptive area by means of large intestinal villi (Klite 1965, Barry 1976, Stutz and Ziswiler 1983-84). However, the animals' level of activity, the type of

Table 4. Food passage rate through the digestive tract in small insectivorous mammals; $t_{5}, t_{50}, t_{90}$, $\mathrm{t}_{100}$ - time (in min) of passage of $5 \%, 50 \%, 90 \%$ and $100 \%$ of marker; BW - body weight $(\mathrm{g}) ;{ }^{1}$ in the case of lack of source data, mean body mass for species are given in parentheses (Kowalski and Ruprecht 1981); ${ }^{2}$ indigo-carmine dye solution injected via orogastric catheter.

\begin{tabular}{|c|c|c|c|c|c|c|c|}
\hline Order and species & $\mathrm{BW}^{1}$ & $\mathrm{t}_{5}$ & $\mathrm{t}_{50}$ & t90 & $t_{100}$ & Food/marker & Source \\
\hline \multicolumn{8}{|l|}{ Chiroptera } \\
\hline \multirow{2}{*}{$\begin{array}{l}\text { Myotis lucifugus } \\
\text { resting }\end{array}$} & $7-8$ & 46 & & & & mealworms/moths & Buchler 1975 \\
\hline & $7-8$ & 144 & & & & mealworms/moths & Buchler 1975 \\
\hline \multirow{3}{*}{$\begin{array}{l}\text { Nyctophilus gouldi } \\
\text { in pregnancy } \\
\text { in lactation }\end{array}$} & $11-12$ & 61 & & & & mealworms/moths & Grant 1988 \\
\hline & $11-12$ & 63 & & & & mealworms/moths & Grant 1988 \\
\hline & $11-12$ & 45 & & & & mealworms/moths & Grant 1988 \\
\hline \multirow{3}{*}{$\begin{array}{l}\text { Eptesicus fuscus } \\
\text { Myotis myotis }\end{array}$} & $15-20$ & 90 & & & & $\operatorname{artificial/\mathrm {BaS}_{4}}$ & Luckens et al. 1971 \\
\hline & 21.1 & 25 & 44 & 77 & & cocroach/basic fucsin & this study \\
\hline & $(28.4)$ & 66 & & & 575 & mealworms $/ \mathrm{BaSO}_{4}$ & Zhukova and Kovtin 1988 \\
\hline in torpor & $(28.4)$ & 126 & & & & mealworms $/ \mathrm{BaSO}_{4}$ & Zhukova and Kovtin 1988 \\
\hline \multirow[t]{2}{*}{ Nyctalus noctula } & $(30.5)$ & 28 & & & & beetles/moths & Cranbrook 1965 \\
\hline & $(30.5)$ & 88 & & & 560 & mealworms $/ \mathrm{BaSO}_{4}$ & Zhukova and Kovtin 1988 \\
\hline ambient temp. $4-6^{\circ} \mathrm{C}$ & $(30.5)$ & 96 & & & & mealworms $/ \mathrm{BaSO}_{4}$ & Zhukova and Kovtin 1988 \\
\hline Molossus major & 10.7 & 15 & & & & /indigo-carmine ${ }^{2}$ & Klite 1965 \\
\hline Chilonycteris rubiginosa & 24.1 & 15 & & & & /indigo-carmine ${ }^{2}$ & Klite 1965 \\
\hline \multicolumn{8}{|l|}{ Insectivora } \\
\hline Sorex minutissim & 2.5 & 25 & & & 110 & insects & Skarén 1978 \\
\hline Cryptotis parva & 4.79 & $95-240$ & & & & meat/insects & Hamilton 1944 \\
\hline \multirow[t]{2}{*}{ Sorex araneus } & 7.5 & 27 & & & 155 & fly larvae/Philoscia & Pernetta 1976 \\
\hline & 7.5 & 53 & & & 224 & fly larvae/Lumbricidae & Pernetta 1976 \\
\hline Neomys fodiens & 12.0 & & 73 & 134 & 255 & $\begin{array}{l}\text { mealworms/basic } \\
\text { fucsin }\end{array}$ & $\begin{array}{r}\text { Kostelecka-Myrcha } \\
\text { and Myrcha } 1964\end{array}$ \\
\hline \multirow[t]{2}{*}{ Elephantulus edwardii } & 38.0 & 30 & 192 & 426 & & Pronutro/Cr51-EDTA & Woodall and Currie 1989 \\
\hline & 38.0 & 111 & 201 & 330 & & $\begin{array}{l}\text { Pronutro/termite } \\
\text { mandibles }\end{array}$ & Woodall and Currie 1989 \\
\hline Antechinus swainsoni & 48.6 & 180 & 435 & 720 & & meat/termite & Cowan et al. 1974 \\
\hline
\end{tabular}


indicator used and the means of measurement affect the results and make it difficult to compare (Buchler 1975, Warner 1981, Woodall and Currie 1989, and others). Using an X-ray method, Zhukova and Kovtin (1988) obtained a time for passage of food 2.5 to 3.0 times longer than that obtained by other authors in the same species (Table 4). This indicates that the measurements may have been taken in inactive bats or that the type of measurement strongly affect the results. The long time for excretion of the rest of the marked food ( $t_{100}$; 8-11.5 hours) may also support this suggestion.

The studies cited (Table 4 ) involved only food transit time ( $t_{0}$ or $t_{5}$ ) or else the time required for complete defecation $\left(t_{100}\right)$. These parameters greatly depend on the indicator used, and on the activity level of the animals and they should not be used in determining the rate of passage of food without estimation of mean retention time ( $t_{50}$ or other parameters discussed by Warner 1981).

It seems that the unusually high rate of digestion in bats when compared to other animals including insectivorous mammals (Table 4; see also Warner 1981 for a review) is connected with the energetic strategy of bats, which consume large amount of insects (up to $50 \%$ of their body weight, see Fenton 1982) during relatively short time of foraging. Firstly, fast digestion enables an increase in consumption rate during foraging. Secondly, bats may decreased their energy expenditures by the reduction of the time of foraging or of the cost of flight caused by decrease in mass of gut contents. On the other hand, the decrease in energy requirements may depend on the possibility of the use of torpor, constraint probably, among others, by the time needed to active digestion of food. This seems to be very important in insectivorous bats feeding on unpredictable food resources, highly dependent on the climatic factors. But this thesis must be supported by further studies on the physiology of digestion in a wider range of species, using comparable methods.

\section{Defecation rate}

Many observations testify that bats fly with an empty alimentary canal to forage, and defecation of feces is most intense after they return to their resting place. The fact that digestion in bats lasts about 5 hours after returning to the diurnal colony support these results (Zharowa 1984). M. lucifugus defecates $80-85 \%$ of total feces during the first 4 hours, and 95\% within 6 hours after returning from foraging (Kunz 1980, Rumage 1979 cited by Kurta et al. 1987). The slightly lower defecation rate in $M$. myotis (Table 1) probably results from its body weight, which is $2-3$ times higher.

Similar results were obtained in individuals from 3 bat species forced to fly during experiments (Alekseeva et al. 1980). During one hour of flight, bats defecated about $20 \%$ of total feces and during two hours outside the colony they defecated up to $40 \%$ of their feces. These data are comparable with the results obtained in the present study (Table 1), even though the bats did not fly during this experiment. Only in a study of Nyctalus noctula was the digestion of food 
considerably slower. The peak of defecation occurred 6-8 hours after feeding (Alekseeva et al. 1980). However, these results contradict information from Cranbrook (1965) on very rapid food passage in N. noctula.

The distribution of defecation rate indicates that under natural conditions a considerable fraction of feces is defecated during foraging, especially in bats which spent part of time roosting in foraging areas. This is important for studies aimed at determining bats' food consumption based on guano accumulated in colonies or on differences in body weight before and after foraging. The results of this study indicates that consumption levels in previous investigations were lowered because it was assumed that very little defecation occurred outside the resting place (e.g. 5\%, Kunz 1980; see also Anthony and Kunz 1977).

Acknowledgements: I wish to thank W. Harmata and J. Weiner for critical reading and valuable comments on the manuscript.

\section{References}

Alekseeva E. A., Panyutin K. K. and Topilina V. G. 1980. [The study of quantitative aspects of bats diet (faecal accumulation in their shelter)]. [In: Rukokrylye. A. P. Kuzyakin and K. K. Panyutin, eds]. Nauka, Moscow: 184-187. [In Russian]

Anthony E. L. P. and Kunz T. H. 1977. Feeding strategies of the little brown bat, Myotis lucifugus, in southern New Hampshire. Ecology 58: 775-778.

Barclay R. M. R., Dolan M. A. and Dyck A. 1991. The digestive efficiency of insectivorous bats. Can. J. Zool. 69: 1853-1856.

Barry R. E. 1976. Mucosal surface areas and villous morphology of the small intestine of small mammals: functional interpretations. J. Mammal. 57: 273-290.

Brisbin I. L. 1966. Energy utilization in a captive hoary bat. J. Mammal. 47: 719-720.

Buchler E. R. 1975. Food transit time in Myotis lucifugus (Chiroptera: Vespertilionidae). J. Mammal. 56: $252-255$.

Buckner C. H. 1964. Metabolism, food capacity, and feeding behaviour in four species of shrews. Can. J. Zool. 42: 259-279.

Castle E. J. 1956. The rate of passage of foodstuffs through the alimentary tract of the goat. Brit. J. Nutr. 10: 15-23.

Castro G., Stoyan N. and Myers J. P. 1989. Assimilation efficiency in birds: a function of taxon or food type? Comp. Biochem. Physiol. 92A: 271-278.

Cowan I. McT., O'Riordan A. M. and Cowan J. S. McT. 1974. Energy requirements of the dasyurid marsupial mouse Antechinus swainsonii (Waterhouse). Can. J. Zool. 52: 269-275.

Cranbrook E. 1965. Grooming by vespertilionid bats. Proc. zool. Soc. Lond. 145: 143-144.

Czerwony B. 1976. [Digestibility of food in a mouse-eared bat (Myotis myotis - Borkhausen).] Unpubl. M. Sc. thesis. Jagiellonian University, Kraków 1-18. [In Polish]

Fenton M. B. 1982. Echolocation, insect hearing, and feeding ecology of insectivorous bats. [In: Ecology of Bats. T. H. Kunz, ed]. Plenum Press, New York and London: 261-285.

Grant J. D. 1988. Food-passage time in Nyctophilus gouldi (Microchiroptera: Vespertilionidae). J. Mammal. 69: 653-655.

Grodziński W. and Wunder B. A., Jr 1975. Ecological energetics of small mammals. [In: Small mammals: their productivity and population dynamics. F. B. Golley, K. Petrusewicz and L. Ryszkowski, eds]. Cambridge Univ. Press, Cambridge: 173-204.

Hamilton W. J. 1944. The biology of the little short-tailed shrew, Cryptotis parva. J. Mammal. 25: 1-7. 
Hanski I. 1984. Food consumption, assimilation and metabolic rate in six species of shrew (Sorex and Neomys). Ann. zool. Fenn. 21: 157-165.

Hawkins A. E. and Jewell P. A. 1962. Food consumption and energy requirements of captive British shrews and the mole. Proc. zool. Soc. Lond. 138: 137-155.

Johnson D. R. and Maxell M. H. 1966. Energy dynamics of colorado picas. Ecology 47: 1059-1061.

Klite P. D. 1965. Intestinal bacterial flora and transit time of three neotropical bat species. J. Bacteriol. 90: 375-379.

Kostelecka-Myrcha A. and Myrcha A. 1964. Rate of foodstuffs through the alimentary tract of Neomys fodiens (Pennant, 1771) under laboratory conditions. Acta theriol. 9: 371-373.

Kowalski K. and Ruprecht A. L. 1981. Order: Bats - Chiroptera. [In: Keys to Vertebrates of Poland. Mammals. Z. Pucek, ed]. PWN - Polish Sci. Publ., Warszawa: 101-154.

Kunz T. H. 1980. Daily energy budgets of free living bats. [In: Proc. 5th Int. Bat Res. Conf. D. E. Wilson and A. L. Gardner, eds]. Texas Tech. Press, Lubbock: 369-392.

Kunz T. H. 1988. Methods of assessing the availability of prey to insectivorous bats. [In: Ecological and behavioral methods for the study of bats. T. H. Kunz, ed] Smithsonian Institution Press, Washington, D.C., London: 191-210.

Kunz T. H. and Nagy K. A. 1988. Methods for energy budget analysis. [In: Ecological and behavioral methods for the study of bats. T. H. Kunz, ed] Smithsonian Institution Press, Washington, D.C., London: 191-210.

Kunz T. H. and Whitaker J. O. 1983. An evaluation of faecal analysis for determining food habits of insectivorous bats. Can. J. Zool. 61: 1317-1321.

Kurta A., Johnson K. A. and Kunz T. H. 1987. Oxygen consumption and body temperature of female little brown bats (Myotis lucifugus) under simulated roost conditions. Physiol. Zool. 60: 386-397.

Luckens M. M., Eps J. van and Davis W. H. 1971. Transit time through the digestive tract of the bat, Eptesicus fuscus. Exp. Med. Surg. 29: 25-28.

Neuhauser H. N. and Brisbin I. L. 1969. Energy utilization in a captive silver-haired bat. Bat Res. News 10: 30-31.

O'Farrell M. J., Studier E. H. and Ewing W. G. 1971. Energy utilization and water requirements of captive Myotis thysanoides and Myotis lucifugus (Chiroptera). Comp. Biochem. Physiol. 39A: $549-552$.

Pagels J. F. and Blem C. R. 1973. Metabolized energy of the big brown bat Eptesicus fuscus (Chiroptera). Comp. Biochem. Physiol. 45A: 497-501.

Pernetta J. C. 1976. Bioenergetics of British shrews in grassland. Acta theriol. 21: 481-497.

Rabinowitz A. R. and Tuttle M. D. 1982. A test of the validity of two currently used methods of determining bat prey preferences. Acta theriol. 27: 283-293.

Sibly R. M. 1981. Strategies of digestion and defecation. [In: Physiological ecology: an evolutionary approach to resource use. C. R. Townsend and P. Callow, eds] Sinauer, Sunderland, Mass.: 109-139.

Skarén U. 1978. Feeding behaviour, coprophagy and passage of foodstuffs in a captive least shrew. Acta theriol. 23: 131-140.

Soholt L. F. 1973. Consumption of primary production by a population of kangaroo rats (Dipodomys merriami) in the Mojave Desert. Ecol. Monogr. 43: 357-376.

Sokal R. R. and Rohlf F. J. 1981. Biometry. 2nd. Freeman and Comp., New York: 1-859.

Stutz H. and Ziswiler V. 1983-84. Morphological and histological investigations of the digestive tract of middle European bats (Mammalia: Chiroptera). Myotis 21-22: 41-46.

Warner A. C. I. 1981. Rate of passage of digesta through the gut of mammals and birds. Nutr. Abstr. Rev. 51B: 789-820.

Woodall P. F. and Currie G. J. 1989. Food consumption, assimilation and rate of food passage in the cape rock elephant shrew, Elephantulus edwardii (Macroscelidea: Macroscelidinae). Comp. Biochem. Physiol. 92A: 75-79. 
Zharova G. K. 1984. Some peculiarities of digestion in bats. Zool. Ž. 63: 1594-1596. [In Russian with English summary]

Zhukova N. F. and Kovtin M. F. 1988. [Influence of different factors on food passage time in insectivorous bats.] [In: Rukokrylye (morfologiya, ekologiya, ekholokatsiya, parazity, okhrana). V. A. Topachevski and M. F. Kovtin, eds]. Naukova dumka, Kiev: 50-54. [In Russian]

Received 21 June 1993, accepted 8 February 1994. 